\section{Injury in low income countries}

The burden of injuries as a major health problem has been recognised in two reports released recently by the World Health Organisation (WHO) and the World Bank. The Global Burden of Disease edited by CJL Murray and $\mathrm{AD}$ Lopez and published jointly by WHO, the World Bank, and Harvard School of Public Health estimates that $10.7 \%$ of al deaths in the developing countries were due to injuries in 1990 as compared with $7.6 \%$ in the developed countries. ${ }^{1}$ The estimates for years of life lost due to injuries as a per cent of the total are reported to be $16 \%$ in established market economies, $20 \%$ in China, $11 \%$ in India, and $14 \%$ in other Asian countries. An ad hoc committee on health research relating to future intervention options established under the auspices of the WHO has published a report Investing in Health Research and Development. ${ }^{2}$ One of the conclusions of the report is that 'the burden due to injuries could equal that due to communicable diseases world-wide by 2020 . In several developing regions including China, and Latin America and the Caribbean, injuries are expected to exceed communicable diseases'

The committee recommends that a special programme or initiative for research, training, and capacity building on injuries should be set up to focus on issues in low income countries.

National governments of most Asian countries have not initiated any major injury control programmes. It is possible that the publication of these reports and associated changes in policies of international organisations would help researchers and health professionals in Asian countries to put pressure on their respective governments to give more importance to injuries as a health problem. However, it will not be very easy to come up with ready made solutions and countermeasures. Road traffic, work practices, and housing patterns in low income countries are different from those prevalent in high income countries. The situation in many low income countries is much more complex than that in those with a high income because of high income differentials and uses of modern technologies along with traditional ones. For example, London has never experienced the traffic patterns prevalent in Beijing today. Therefore, it is very necessary for professionals in low income countries to do a great deal of original work to come up with countermeasures that are feasible and suit these new conditions. International collaboration to share ideas and experiences would certainly help along with training courses in basic principles of injury control.

DINESH MOHAN

Centre for Biomedical Engineering and WHO Collaborating Centre, Indian Institute of Technology New Delhi 110016

1 Murray CJL, Lopez $\mathrm{AD}$, eds. The global burden of disease: a comprehensive assessment of mortality and disability from diseases, injuries and risk factors in 1990 and projected to 2020. Cambridge, MA: Harvard University Press, 1996.

2 Ad Hoc Committee on Health Research Relating to Future Intervention Options. Investing in to Future Intervention Options. Investing in health Organisation, 1996.

\section{Southern African report}

The editorial in a recent issue of the Lancet related the United Nations' (UN) renewed efforts to resurrect basic living standards in sub-Saharan Africa. Certainly the current statistics are enough to sadden and shock even the toughest 'aid' worker. No access to clean water for $52 \%$ of Africans, $68 \%$ without proper sanitation, 50 million children with protein energy malnutrition, maternal mortality rates of $62-1000$ per 100000 live births - the list goes on. Not so much a 'dark' continent any longer, Africa seems rather to have become invisible to the captains of international industry and other investors who cite political instability, shaky infrastructure, and rampant corruption as justifiable reasons for their reticence. The UN Systemwide Special Initiative on Africa lauched in 1996 will include initiatives to support, among other priorities, education, health, security, and informatics throughout the poorest regions of Africa. This undertaking is fuelled by an operating budget of $\$ 25$ billion, and might be the continent's best (and last) opportunity to climb out of the abyss. Might Africa even become a SAFE place for children?

Against this background, the 18th African Health Sciences Congress held in Cape Town in April predictably featured a cornucopia of health issues, from dental caries in city children to the control of camel trypanosomosis. Interest in both intentional and nonintentional injury was well represented in paper and poster form, but virtually all reports were curiously open ended as far as appropriate safety solutions and implementation were concerned. In discussion, many delegates expressed both a common yearning for better, representative injury data, and desperation at lack of resources to realise safety initiatives. By sheer coincidence, a paper presented in a parallel session and entitled 'Health Information Systems - the Megalomanic Options' took a sour view of obscenely expensive Western-style information systems which have failed to play any mean ingful role in Southern Africa. Senior author Arthur Heywood who lectures at the University of Western Cape School of Public Health made a plea for 'more elementary and locally relevant information systems using a participatory process at local and distric levels'. Any African injury researcher would do well to set their sights slightly lower, accumulate representative local data, and avoid the temptation to describe or quantify injury on a national scale.

A draft report from the Safe Packaging Conference held earlier this year in Cape Town includes a list of recommendations aimed at protecting children from hazardous substances locally available. These include lobbying for tighter government legislation on safe packaging, labelling and classification, creation of a national database on accidental poisoning, preservation of existing poison information centres (recent victims of health service rationalisation), and industry safety regulations. Any reader who would like a full copy of the document is welcome to write to me at the address below.

The University of South Africa Health Psychology Unit hosted a training course in injury control and violence prevention in March, attracting health workers from Maputo and Zimbabwe as well as South Africa Delegates had the benefit of being guided in basic principles by Professor Dinesh Mohan and Dr Geetam Tiwari, both of the Indian Institute of Technology, and who acted as coordinators and primary trainers. Issues highlighted during discussion and conse- quently identified for long term action included the establishment of a Southern African Injury and Violence Control Network - an exciting and overdue initiative, and one of which I shall provide some detai in my next report.

DAVID BASB Acting Director, CAPFSA Department of Paediatric Surger Rondebosch 7700, South Afrito

\section{LETTERS TO THE EDITOR}

More Safe Communities programs Scandinavia have been evaluated: repeating the results from Falköping

EdITOR, - The first Safe Community program that we know of so far was developed the municipality of Falköping, Sweden. Th ideas behind the program were taken up to communities in countries like Norway, Den mark, France, the UK, Canada, Australi@ and New Zealand, among others. Independently, programs were developed in countri६g like Thailand, Indonesia, and later Souṭ̂ America.

Much of the success in spreading this safety promotion idea was that the program descriptions were able to point to evaluation of effects, sometimes related to proces Lothar Schelps' academic thesis was based on an injury surveillance that started in 1978 The program showed a $27-28 \%$ reduction of injuries in the transport, home, and industria safety areas in 1981. In the control areas the were no effects!

The idea was picked up in Norway, and the Vaeroy study was not only able to repeat the effects from Falköping, but also to show ât extensive long term effect with $58 \%$ reduction after eight years. ${ }^{2}$ Further programs in Swळ den were also evaluated. For example Lidköping, a study on child injuries showe on average, a $2.1 \%$ (boys) to $2.4 \%$ (girlî) annual decrease of injuries leading to hospita admissions from 1983 to $1991 .^{3}$

In 1995, another doctoral thesis was released, this time from the University of Troms, Norway. ${ }^{4}$ It is based on five papers from international journals, focusing on effectis of intervention over up to eight years from the Harstad Injury Prevention Study. Burns were reduced by $53 \%$, transport injuries by $27 \%$, fall fractures by $26 \%$, and downhill skiirfos injuries by $15 \%$. The corresponding injury rates increased in the control area (Trond heim) for traffic and fractures seemed to be unaltered for burns in children.

In February 1996, during the Third Intef national Conference on Injury Prevention and Control in Melbourne, Australia, the Dane showed their first data from the 5-Comm nity-Project (presentation by B Frimodt-MoD ler, Injury Surveillance Unit, National Boare of Health, Copenhagen). During 18 months, in 1990-2, in the intervention areas hom and play injuries among children $0-5$ yeaf were reduced by $8 \%$, and bicycle injuries $6-16$ years by $54 \%$.

Thus, different Scandinavian countries appear to have achieved astonishing results attacking injury problems at the local com- 
munity level. We look forward to more studies from other regions of the world.

\section{LEIF SVANSTRÖM Karolinska Institute, Department of Public Health Sciences, Divison of Social Medicine, Stockholm, Sweden} (Correspondence to: Professor Svanström at Social
Medicine Kronan, S 17283 Sundbyberg, Sweden)

1 Schelp L. Epidemilogy as a basis of evaluation of a community intervention on accidents. (Thesis.) Solna and Sundbyberg, Sweden: Karolinsk Institute, Department of Social Medicine, Kronan Health Centre, 1987.

2 Tellness G. An evaluation of an injury prevention campaign in general practice in Norway. Fam campaign in general

3 Svanström L, Ekman R, Schelp L, Lindström Å. The Lidköping Accident Prevention ProgramA community approach to preventing childhood injuries in Sweden. Injury Prevention 1995; 1: $169-72$.

4 Ytterstad B. The Harstad Injury Prevention Study: hospital-based injury recording and community-based intervention. Troms, Norway: Institute of Community Medicine, University of Troms, 1995: 33. (Thesis.)

\section{Random thoughts ${ }^{1}$ on bicycle helmets}

EDITOR, - If we get bicycle helmet laws, don't we then need pedestrian helmet laws? Lots of child pedestrians, many more than child bicyclists, are hurt by cars.

Or is the answer to get drivers not to hit people? (Or kids, if you want to limit it.) Isn't that what's needed, hard as it is?

Thanks for thinking about, and taking a position on, a hard subject.

DON HARVEY

Orange County Bicycle Coalition $630 S$ Glassell, Suite 100 Orange, $C A$ 92666, USA

1 Pless IB. Random thoughts. Injury Prevention 1997; 3: 73 .

\section{PEDNET}

\section{Threads from the Pedestrian Network} (PEDNET)

The lively discussions on PEDNET frequently include safety issues. One recent topic focused on efforts to 'encourage' motorists to stop for pedestrians in crosswalks. Much of the discussion about how this could be achieved involved elements of epidemiology, education law enforcement, and environmental modification. It was evident, however, that concerns about violations of crosswalk rules differ widely. Whereas Injury Prevention readers worry about the injuries resulting from these violations, others worry about dangerous drivers scaring walkers. Reducing exposure is one way to prevent injuries, but it is difficult to imagine discouraging walking as a prevention strategy! Indeed, advocates oppose injury prevention programs that rely on deterrence (for example avoid walking at night)

Sally Flocks (of Walk Atlanta, pedsatl@ aol.com) initiated a PEDNET thread by asking about the use of signs to mark crosswalks. Most participants agreed the current sign used in North America (a figure walking between two lines) fails to convey that the law requires motorists to stop for the pedestrian. Participants proposed other signs that might be better: I reported that one study ${ }^{1}$ showed that a sign reading 'Stop Here for Pedestrians' reduced conflicts by $80 \%$.

Another part of the discussion focused on law enforcement. An exchange of information between advocates and researchers was valuable. A paper by Britt et al showed that traffic law enforcement aimed at increasing motorist compliance with pedestrian traffic laws failed to increase drivers' willingness to stop for pedestrians. $^{2}$ The authors state that altering the design features of the roadway to achieve traffic calming is likely to be more effective. Thus further contributions to this thread focused on crosswalk design and other environmental issues. Here's where the international perspective of PEDNET and the readers of Injury Prevention can be beneficial Crosswalk design varies between countries. The US relies mostly on painted markings on the road surface, whereas British crosswalks are more elaborate and often include flashing (Belisha) beacons. Unfortunately, by international standards, both of these countries have higher than expected pedestrian injury rates.

Another thread addressed the role of legal liability. In much of Europe, the motorist is at fault for striking a child, whereas that is not the case in Britain and North America. More information is needed to determine the role of legal responsibility in injury reduction. Perhaps an Injury Prevention reader can help.

PEDNET participants also learn of the latest developments in politics. In many countries, transportation policy has become controversial. After the long, hot, and smogridden summer of 1995 in Europe, many people saw a connection between transportation policy accommodating car use and damage to the environment. Some protested road construction projects, notably at Twyford Down in Britain. This road project would have saved three minutes on the journey between London and Southampton, but would have sacrificed an area of historical and ecological importance. Protesters frequently framed the arguments against road construction in term of injuries, and were successful in making transportation spending a campaign issue in the British elections.

In the US, pedestrian safety has also become a political item. The national transportation advocates, Surface Transportation Policy Program (STPP), received press coverage for determining that people are nearly twice ( 1.6 times) as likely to be killed by a car while walking than by a stranger with a gun. Nevertheless, in all, just $10 \%$ of US federal safety money is spent on pedestrian safety even though pedestrians account for $14 \%$ of motor vehicle related fatalities. In urban areas, the disparity increases. In New York City, pedestrian deaths are $53 \%$ of the traffic fatalities, but the city spends only $5 \%$ of the safety funds on pedestrians. Other cities were even less likely to invest in pedestrian safety, and 36 states spent none of their federal safety money on pedestrian safety. Although 10 times as many pedestrians die than people in railroad crossings, one tenth as much is spent on pedestrian safety. The STPP have asked for pedestrian safety projects, such as traffic calming, to receive federal safety funds at least proportionally to the number injured. Wouldn't that amount of money do wonderful things for pedestrians? Their report Mean Streets; Pedestrian Safety and Reform of the Nation's Transportation Law is available on the world wide web at www.ewg.org.

PETER JACOBSEN PO Box 712433 Los Angeles,
1 Van Houten R, Malenfant L. The influence of signs prompting motorists to yield before conflicts at crosswalks with flashing amber. Accid Anal Prev 1992; 24: 217-25.

2 Britt JW, Bergman AB, Moffat J. Law enforcement, pedestrian safety, and driver compliance with crosswalk laws: evaluation of a four-year campaign in Seattle. Trans Res Rec 1995; 1485: $160-7$.

\section{$\mathrm{BOOK}$ REVIEWS}

Injury Control-A Global View. By Lawrence R Berger and Dinesh Mohan. (Pp 292; US\$35.) Oxford University Press, 1996. ISBN 0-19-563680-5.

Published in 1996, and initiated by the World Health Organisation (WHO) Injury Prevention Program, the goal of this book was, in the words of the foreword written by Claude Romer, to 'provide an overview of the current status and trends of injuries in countries throughout the world'. This it does and does well. It is also intended to 'discuss the value and limitations of injury data, the scientific basis of injury research and control, and the role of all health professionals in addressing injuries as a public health problem'. Again, a clear success. Whether it succeeds in its third goal-to reach the intended broad target audience-is another matter. The dust cover suggests it would be of interest to health professionals, policy makers, community health workers, and students of medicine, nursing, and public health. We fear too many of these do not even know this book exists.

Injury Control effectively outlines the trends in injury in both the lower income countries and higher income countries, delineating the similarities and differences in the etiology and outcomes of injury in the two world areas. It is grounded in the theoretical framework of the Haddon matrix which, when combined with the chapters on 'Translating Concern into Action' and 'Injury Control Interventions' make it especially useful to program managers. Moreover, the numerous tables and pictures make it accessible to the novice and the appendices add to its value.

There are three positive features of this book. First, it is well written, coupling clarity with scientific rigor. Second, it achieves a balance between the problems unique to high and low income countries and those that are shared. Third, it is well illustrated, using clear charts and tables alongside many excellent photographs.

Information pertinent to low income countries is contrasted with that from high income countries. The rationale for doing so is that the profiles in each of these settings is different, and thus their respective research efforts should also differ. At the same time, the book makes evident that many problems are multinational, so that 'pesticides used by South American farmers appear in foods on dinner tables in Europe and North America', and, conversely, 'automobiles made in Japan, Korea, and the USA traverse the roads of Thailand and Argentina'.

However, while it addresses the special socioeconomic influences on injury in the low income countries it does not delve deeply into underlying issues such as religion 